\title{
Hymenolobium discolor W. Rodrigues \& N. Mattos, nova espécie de Leguminosae da Amazônia.
}

\author{
William A. Rodrigues (") \\ Nilza Fischer Mattos $\left({ }^{* *}\right)$
}

\begin{abstract}
Resumo
Hymenolobium discolor W. Rodrigues \& N. Mattos (L.eguminosae), espécie arbórea da mata de terra firme cos arredores de Manaus, Amazonas, Brasil, é descrita neste trabalho como nova para a Ciência. Difere da espécie mais próxima, $\mathbf{H}$. complicatum Ducke, principalmente, pelas folhas discolores, pela dimensão menor das peças florais e pelo ovário completamente seríceo.
\end{abstract}

Dentre as coleções do INPA do gênero Hymenolobium Bentham (Leguminosae), havia um espécime que se supunha espécie nova, a qual veio a confirmar-se durante a revisão das espécies do gênero ocorrentes no Brasil feita pela júnior deste trabalho (Mattos, 1979).

A descrição dessa nova espécie é apresentada a seguir.

Hymenolobium discolor W. Rodrigues e N. Mattos.

Arbor ca. $25 \mathrm{~m}$ alta. Rami juveniores nigrescentes. Folia 2-7 foliolata, glabrerrima; petioli $4,0-7,5 \mathrm{~cm}$ longi, nigrescentes sulcati; petioluli $0,3-0,8 \mathrm{~cm}$ longi, nigrescentes; laminae $6-11 \mathrm{~cm}$, longae $1,9-4,6 \mathrm{~cm}$ latae, oblongae vel obovato-oblongae, supra nitidae, infra fulvescentes vel fuscatae, coriaceae, ad basin acutae, obtusae vel sub-rotundatae, ad apicem subacuminatae curvataeque, reticulato-venosae; costa supra impressa, subtus prominens; nervi secundarii multi, utrinque prominuli. Inflorescentiae paniculatae, terminales, sericeo-pubescentes $8-11 \mathrm{~cm}$ longae; pedunculi, pedicelli calycesque sericeo-pubescentes; pedicelli 0,4 $0,6 \mathrm{~cm}$ longi. Calyx $0,4-0,5 \mathrm{~cm}$ longus, campanulatus, 5- dentatus, dentibus obtusis. Corola purpurea (fide collectoris), glabra; vexillum $0,7-0,8 \mathrm{~cm}$ longum, suborbiculare, ad apicem emarginatum, ungue $0,2-0,3 \mathrm{~cm}$ longo; alae 0,6 $0,8 \mathrm{~cm}$ longae, falcatae ungue $0,2-0,3 \mathrm{~cm}$ longo; carina $0,9-1,0 \mathrm{~cm}$ longa, ungue $0,3-0,4 \mathrm{~cm}$ longo; stamina $10,0,7-1,2 \mathrm{~cm}$ longa, monadelpha, 5 alterna longiora, 1 prope basin tubi connato; ovarium ca. $0,5 \mathrm{~cm}$ longum, lineare, omne dense sericeum, gynophoro $\mathrm{ca}$. $0,2 \mathrm{~cm}$ longo, sericeo; stylus $0,3-0,5 \mathrm{~cm}$ longus, curvatus, stigmate capitato, diminuto; fructus non visi.

Árvore de $25 \mathrm{~m}$ de altura. Raminhos terminais enegrescidos, glabros. Folhas 2-7 fo. lioladas, glabérrimas; pecíolo enegrescidos, sulcados, de $4,0-7,5 \mathrm{~cm}$ de comprimento; peciólulos enegrescidos de $0,3-0,8 \mathrm{~cm}$ de comprimento; folíolos alternos ou opostos de $6-11 \mathrm{~cm}$ de comprimento, $1,9-4,4 \mathrm{~cm}$ de largura, oblongos ou obovado-oblongos, brilhantes na página superior, pardo-amarelados na página inferior, coriáceos, agudos, obtusos ou subarredondados na base, subacuminados e curvados no ápice, reticuladovenosos, nervura mediana impressa na página superior, saliente na inferior, nervuras secundárias numerosas, promínulas nas duas faces. Inflorescências paniculadas, terminais, seríceo-pubescentes, de $8-11 \mathrm{~cm}$ de comprimento; pedúnculos, pedicelos e cálice seríceo-pubescentes. Pedicelos de 0,4-0,6cm de comprimento. Cálice de $0,4-0,5 \mathrm{~cm}$ de comprimento, campanulado, 5-dentado, com dentes obtusos. Corola roxa (segundo o coletor), glabra; vexilo de $0,7-0,8 \mathrm{~cm}$ de comprimento, suborbicular, emarginado no ápice e unguiculado na base, unguículo de $0,2-0,3 \mathrm{~cm}$ de comprimento, tênue; pétalas alares de $0,6-0,8 \mathrm{~cm}$ de com. primento, falcadas, unguiculadas, unguículo de $0,2-0,3 \mathrm{~cm}$ de comprimento, pétalas carenais de $0,9-1,0 \mathrm{~cm}$ de comprimento, unguiculadas, un.

(") - Instituto Nacional de Pesquisas da Amazônia, Manaus.

("*) - Instituto de Pesquisas de Recursos Naturais Renováveis, "Ataliba Paz", Porto Alegre. 


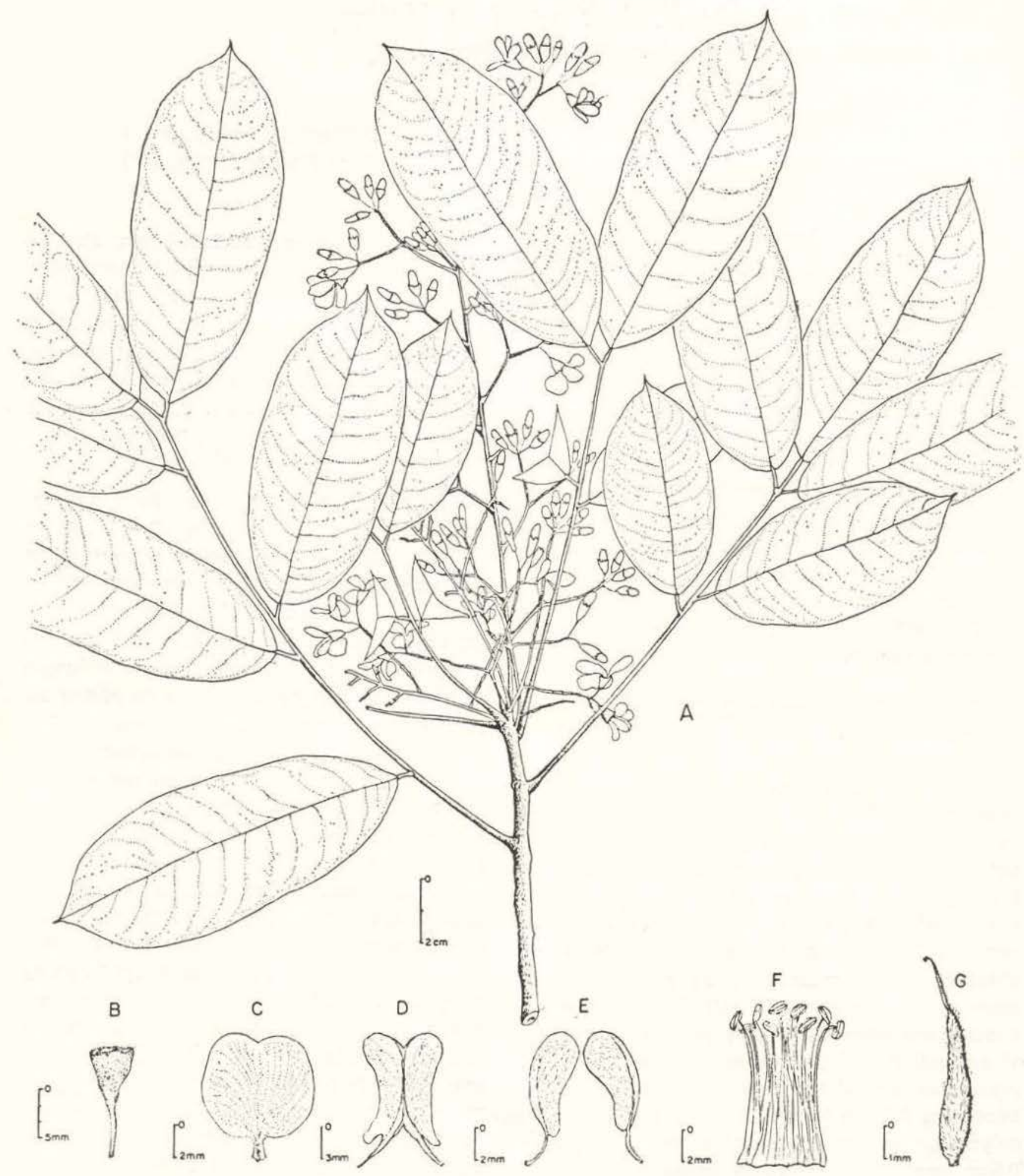

Fig. 1 - Hymenolobium discolor W. Rodr. \& N. Mattos, n. sp. (O.P. Monteiro s/n., INPA 27365). A - ramo florifero; B - cálice; C - vexilo; D - carena; E - alas; F - feixe estaminal aberto; G - pistilo. 
guículo tênue de $0,3-0,4 \mathrm{~cm}$ de comprimento; estames 10 , sendo 9 unidos até mais ou menos $2 / 3$ do tamanho do androceu e o vexilar unido apenas perto da base; ovário de mais ou menos $0,5 \mathrm{~cm}$ de comprimento, linear, inteiramente seríceo, curtamente estipitado, ginóforo cie cerca de $2 \mathrm{~mm}$ de comprimento, seríceo; estilete curvo de $0,3-0,5 \mathrm{~cm}$ de comprimento, glabro; estigma capitado, muito pequeno; fruto desconhecido.

Tipo: Osmarino P. Monteiro $\mathrm{s} / \mathrm{n}$. (holótipo: INPA 27365; isótipo: IPRN). Brasil, Amazonas, estrada Manaus-Itacoatiara $\mathrm{km} 70$, num varadouro à direita. Árvore de $25 \mathrm{~m}$ de altura, $26 \mathrm{~cm}$ de diâmetro (D.A.P.); flores roxas; mata de terra firme, solo argiloso. Nome vulgar: sucupira. Flores em 14 de maio de 1965.

Esta espécie difere de sua espécie mais próxima, H. complicatum Ducke, principalmente pelas folhas bicolores, dimensões destaca- damente menores das peças florais e pelo ovário inteiramente seríceo.

\section{SUMMARY}

The authors describe the new amazonian species, Hymenolobium discolor W. Rodrigues \& N. Mattos, closely related to $\mathbf{H}$. complicatum Ducke, from which it differs mainly by the discolor leaves, the smaller size of the floral pieces, as too by the ovary densely sericeous.

\section{BIBLIOGRAFIA}

MATtos, Nilza Fischer

1979 - O gênero Hymenolobium Bth. (Leguminosae) no Brasil. In Roessléria, Porto Alegre, 3 (1): 13-53, 17 figs.

(Aceito para publicação em 12/11/80) 